\title{
Pulmonary Arterial Hypertension Induced by Distention of the Main Pulmonary Artery in Conscious Newborn, Young, and Adult Sheep
}

\author{
CRAIG E. JURATSCH, ${ }^{(37)}$ GEORGE C. EMMANOUILIDES, DONALD W. THIBEAULT, \\ BARRY G. BAYLEN, JAMES A. JENGO, AND MICHAEL M. LAKS \\ From the Divisions of Cardiology, Departments of Medicine and Pediatrics, Harbor-UCLA Medical Center, Torrance, \\ California, UCLA School of Medicine, Los Angeles, California, USA
}

\begin{abstract}
Summary
Distention of the main pulmonary artery by balloon inflation in sheep results in presumably reflex elevation of pulmonary arterial pressure and resistance distal to the balloon. This response to main pulmonary artery distention is significantly greater in newborn lambs than in older lambs or adult sheep. In several of the newborn lambs, pulmonary artery pressure was raised to suprasystemic levels. Further, in some of the newborn animals, these increases in pulmonary artery pressure and resistance were sustained after deflation of the balloon for periods up to $2 \mathrm{hr}$. The functional significance of this pulmonary hypertension reflex was not elucidated. However, the data strongly suggest that this reflex may contribute to the maintenance of high pulmonary vascular resistance during fetal and early neonatal life.
\end{abstract}

\section{Speculation}

Proximal distention of the main pulmonary artery induces a positive feedback reflex which significantly elevates pulmonary artery pressure and resistance. We postulate that this reflex operates in conjunction with hypoxia to maintain high pulmonary vascular resistance in the fetus. It is possible that at birth this reflex mechanism operates in reverse to help lower the pulmonary vascular resistance smoothly, thus avoiding volume overload of the neonatal lungs and left ventricle. Finally, we postulate that this reflex may play a role in the pathogenesis of the persistant fetal circulation syndrome (7).

In the conscious adult dog distention of the proximal main pulmonary artery, near the bifurcation, by a partially inflated balloon, results in a significant elevation of pulmonary artery pressure distal (as well as proximal) to the balloon $(19,20,22)$. This elevation in pressure is produced by an increase in pulmonary vascular resistance which occurred without significant change in right ventricular end-diastolic pressure, aortic pressure, and cardiac output. Left atrial pressure either did not change or decreased. We have reported that stepwise balloon distention of the main pulmonary artery results in step increases in pulmonary artery pressure downstream from the balloon (22) and that this phenomenon is most likely due to sympathetic reflex pulmonary vasoconstriction $(19,20)$

A prominent feature of this pulmonary artery distention reflex is its presumably positive feedback nature. The term "positive feedback" is used to describe this pulmonary vascular pressor reflex because it appears to depend on the excitation of stretch receptors upstream from the pulmonary vascular bed to cause the constriction of the downstream pulmonary vessels such that the greater the distention of the main pulmonary artery the greater the downstream vasoconstriction. Consideration of the implications and significance of the existence of such a pulmonary arterial stretch receptor system to raise pulmonary vascular resistance, via positive feedback mechanisms, as shown in the dog, poses the following questions: (1) is this pulmonary hypertension reflex present in other species? (2) is this reflex more active in the newborn than adult?

If the answer to the above questions is yes, then the presence of this reflex could be most important during fetal and neonatal life where the pulmonary vasculature is known to be most reactive (4, $13,24,25,32,36$ ).

To our knowledge, this reflex has not been looked for in newborn animals. Therefore, the purpose of the present study was to determine the operational range of this reflex in sheep, particularly during the neonatal period.

\section{MATERIALS AND METHODS}

Ten healthy newborn term lambs, four 3-month-old lambs, and four adult sheep were studied in the awake state with sufficient local anesthesia, lidocaine $(2 \%)$, to prevent any discomfort. One additional adult sheep was studied under sodium pentobarbital anesthesia $(28 \mathrm{mg} / \mathrm{kg})$.

\section{DELIVERY AND CATHETER IMPLANTATION IN TERM LAMBS}

The age of the newborn lambs ranged from $2 \mathrm{hr}$ to 5 days. Three of these newborns were born spontaneously, and the rest were delivered by caesarean section from ewes with timed pregnancies. During delivery, the pregnant ewe was given low spinal anesthesia using 4 to $8 \mathrm{mg}$ of tetracaine hydrochloride and $0.2 \mathrm{mg}$ of epinephrine diluted in $2.0 \mathrm{ml}$ of $10 \%$ glucose, under surgically aseptic conditions. A laparotomy was performed in the left lateral flank, and the fetus delivered by hysterotomy. The hysterotomy and laparotomy were then sutured, and the ewe was allowed to recover for future study.

Nasal pharyngeal suction was immediately performed on the exteriorized fetus, but the umbilical cord was cut only after neonatal respiratory function was established. However, in three of these newborn lambs under 140 days of gestation, mechanically assisted ventilation (Bird-Mark VIII infant respirator) with $100 \%$ oxygen was required.

Immediately after delivery either a 5 French or 7 French pediatric Swan-Ganz end-hole catheter (Edwards Laboratory) was inserted into the jugular vein and advanced to the main pulmonary artery under fluoroscopic control. When carefully held to maintain its position in the main pulmonary artery and when the balloon was inflated to partially obstruct flow, the catheter enabled proximal distention of the pulmonary artery and measurement of the pulmonary artery pressure distal to the balloon (Fig. I). A catheter was also positioned in the aorta via an umbilical artery. If, however, the umbilical artery was unavailable, as in the older lambs, the catheter was positioned via a carotid artery. This procedure required a small cervical incision to be made under the local anesthesia as described. 


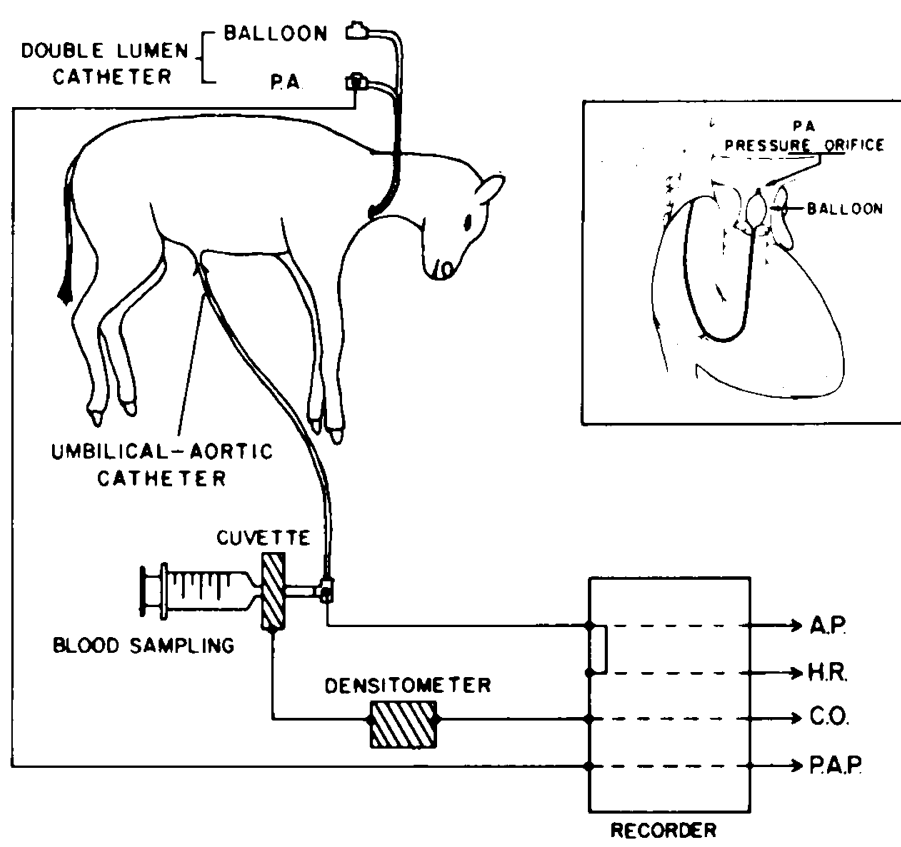

Fig. 1. Experimental preparation. Animals were studied awake using local anesthesia (Lidocaine $2 \%$ ). Catheters were placed in the main pulmonary artery and the thoracic aorta via a jugular vein and umbilical artery, respectively. If the umbilical artery was unavailable as in older animals and adult sheep, the aortic catheter was inserted through a carotid artery. Inset, position of the balloon in the main pulmonary artery of the newborn lamb which was maintained proximal to the bifurcation by manual traction. In 3-month-old and adult sheep, a catheter with a specially designed extended tip was placed in the main pulmonary artery. Wedging the extended tip in a small branch of the pulmonary artery stabilized the balloon position in the main pulmonary artery so that manual traction was not necessary.

\section{CATHETER IMPLANTATION IN 3-MONTH-OLD LAMBS AND ADULT SHEEP}

In the larger older animals, distention of the main pulmonary artery and measurement of pulmonary artery pressure distal to the balloon was accomplished using a specially designed triple lumen balloon catheter (Edwards Laboratory). Briefly, the balloon catheter was introduced into the right jugular vein through a small cervical incision, and the tip of the catheter was wedged under fluoroscopic control in a small branch of the pulmonary artery $(20,22)$. Wedging the tip of this catheter in a small pulmonary artery stabilizes the position of the balloon in the main pulmonary artery during repeated inflation and deflation. The main pulmonary artery pressure was measured distal to the balloon. In addition, a catheter was also placed in the descending aorta via the right carotid artery.

During incremental balloon inflation in the main pulmonary artery, each step increase in balloon volume over a minimum threshold (usually around $3 \mathrm{ml}$ of balloon volume) results in a step increase in pulmonary artery pressure up to the point of complete occlusion of the artery (22). In the present study, the balloon was inflated sufficiently to obtain the maximal possible increase in pulmonary artery pressure without decrease in aortic pressure.

\section{HEMODYNAMIC MEASUREMENTS}

The pulmonary artery and aortic pressure catheters were connected to strain gauge transducers (Statham, P23dB) leveled to the right atrium. Heart rate was determined from a standard lead II ECG tracing. Cardiac output was determined by the indocyanine green dye technique. Dye was injected into the right ventricle in adults and 3-month-old lambs and into the pulmonary artery of the newborn lamb (16). Dilution curves were obtained by with- drawing blood through the aortic pressure catheter and a Waters model XC302 densitometer with a Sage-Waters model 267 withdrawal pump. The strain gauges and densitometer were connected to a Hewlett-Packard model 8890A optical recorder (Fig. 1).

Steady-state pressures, heart rate, and cardiac output were determined during a control period and during and after distention of the main pulmonary artery. The duration of balloon distention did not exceed 8 to $10 \mathrm{~min}$.

Data were obtained from a total of 52 separate experiments in 19 animals of both sexes and three age groups: newborn, 3 months old, and adult. Statistical significance of the data was determined within groups by the paired $t$ test (one tailed), whereas differences between groups were determined by analysis of variance.

\section{RESULTS}

\section{CHARACTERISTIC RESPONSES TO PROXIMAL DISTENTION OF THE MAIN PULMONARY ARTERY}

Distention of the proximal pulmonary artery wall by a partially inflated balloon in the main pulmonary artery (MPA) invariably induced a marked elevation in pulmonary artery pressure downstream from the balloon (Figs. 2 to 5 ).

An example of the response to MPA distention is presented for each age group studied (Figs. 2 to 4 ). In general, a rapid rise in the downstream pulmonary artery pressure occurred within one to two heart beats after the onset of balloon inflation with a steady state of pulmonary hypertension being reached within $45 \mathrm{sec}$. In every case, both the systolic and diastolic pressures rose. With the exception of some animals in the newborn group, the elevated pulmonary artery pressure returned to near control levels with a similar time course after deflation of the balloon.

\section{RESPONSES IN ADULT SHEEP}

In the adult sheep group (Fig. 5), MPA distention increased the downstream mean pulmonary artery pressure from $17 \pm 1$ to 25 $\pm 1 \mathrm{~mm} \mathrm{Hg}(P<0.05)$. Small but significant increases occurred in both aortic pressure and heart rate (Table 1). Mean aortic pressure increased from $127 \pm 3$ to $133 \pm 5 \mathrm{~mm} \mathrm{Hg}(P<0.05)$ whereas heart rate rose from $109 \pm 13$ to $116 \pm 13$ beats $/ \mathrm{min}(P$ $<0.05$ ). However, because cardiac output was not significantly changed by MPA distention (Table 1), the calculated pulmonary resistance increased significantly from $2.78 \pm 0.62$ resistance units (RU) to $4.08 \pm 0.89 \mathrm{RU}(P<0.05)$, (Fig. 6), an increase of $51 \%$ above control levels (Fig. 7).

\section{RESPONSES IN 3-MONTH-OLD LAMBS}

The response to MPA distention in 3-month-old lambs is with minor exceptions similar to that obtained in the adult sheep (Figs. 5 to 7; Table 1). In these animals, MPA distention increased the downstream mean pulmonary artery pressure from $19 \pm 1$ to 26 $\pm 1 \mathrm{~mm} \mathrm{Hg}(P<0.05)$ (Fig. 5). Mean aortic pressure was not significantly changed: $93 \pm 4 \mathrm{~mm} \mathrm{Hg}$ before MPA distention and $94 \pm 3 \mathrm{~mm} \mathrm{Hg}$ during MPA distention. Heart rate significantly increased from $121 \pm 4$ to $128 \pm 5$ beats $/ \min (P<0.05)$ whereas cardiac output significantly increased from $3.98 \pm 0.34$ to $4.35 \pm$ 0.28 liters $/ \mathrm{min}(P<0.05)$ (Table 1$)$. Notably, even in the presence of an increase in cardiac output, MPA distention caused a significant increase in the calculated pulmonary resistance from $4.61 \pm$ 0.36 to $6.16 \pm 0.21 \mathrm{RU}(P<0.05)$, an increase of $40 \%$ above control levels (Fig. 7). There was no significant difference between the resistance responses of this group and the adult sheep group by analysis of variance (Fig. 7) $(P>0.05)$.

\section{RESPONSES IN NEWBORN LAMBS}

As in the adult and 3-month-old groups, distention of the main pulmonary artery in newborn lambs including those animals ventilated with $100 \% \mathrm{O}_{2}$ induced marked pulmonary hypertension (Figs. 2 and 5 to 7). The mean pulmonary artery pressure, in this group, increased from $35 \pm 3$ to $49 \pm 3 \mathrm{~mm} \mathrm{Hg}(P<0.05)$ (Fig. 

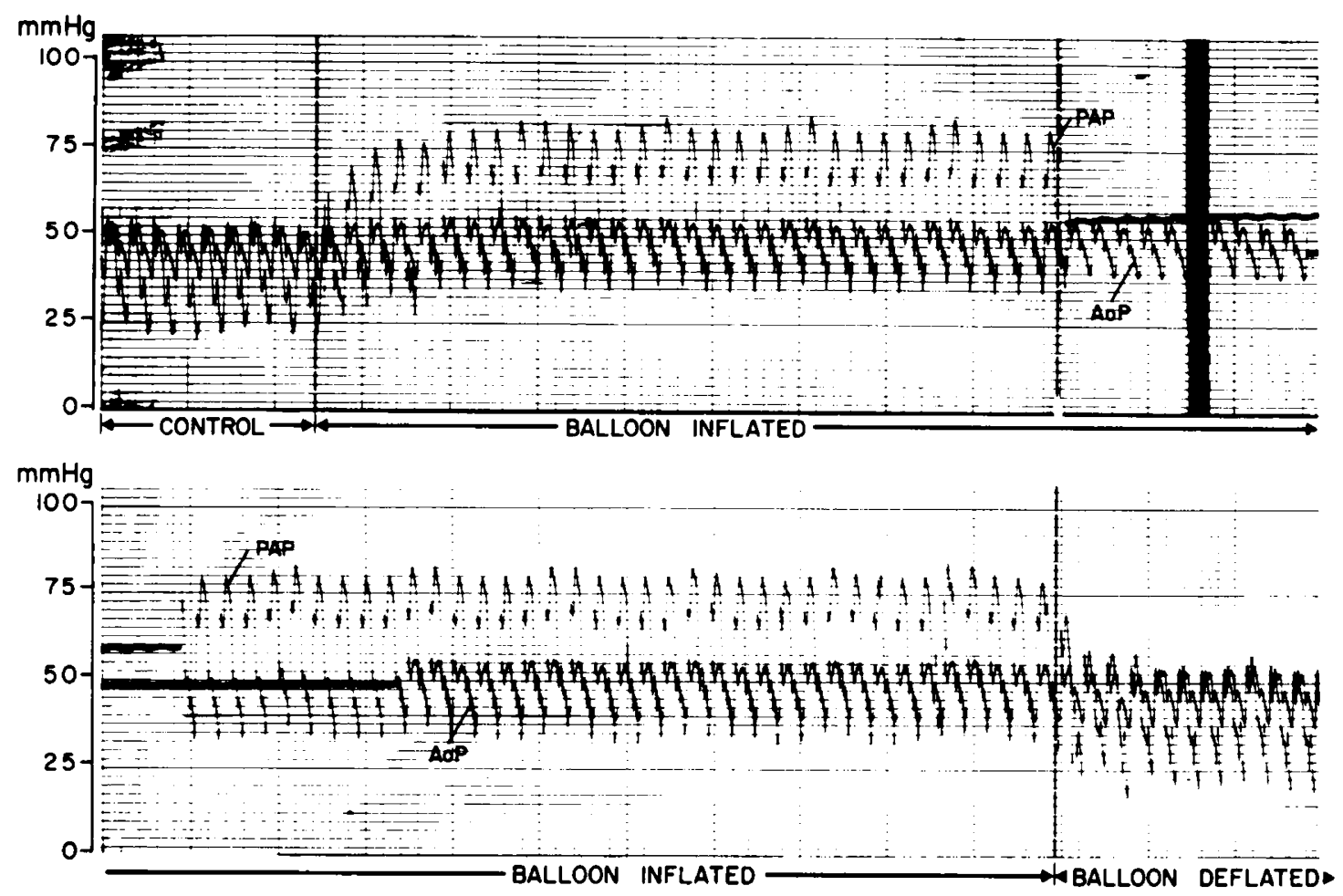

Fig. 2. Response to main pulmonary artery distention in an awake newborn lamb. This lamb, delivered by Cesarean section, was only $2 \mathrm{hr}$ old. Upper panel, rapid onset of the response; lower panel, off response. Before MPA distention, the pulmonary artery pressure was similar to but lower than the aortic pressure. However, with MPA distention, the pulmonary artery pressure markedly increased from $53 / 25$ to $84 / 38 \mathrm{~mm} \mathrm{Hg}$ whereas aortic pressure did not appreciably change $(<3 \mathrm{~mm} \mathrm{Hg}$ ). Remarkably, the mean pulmonary artery pressure reached levels equal to or above the aortic systolic pressure. After balloon deflation, the normal relationship between the pulmonary artery and aortic pressures was reestablished.

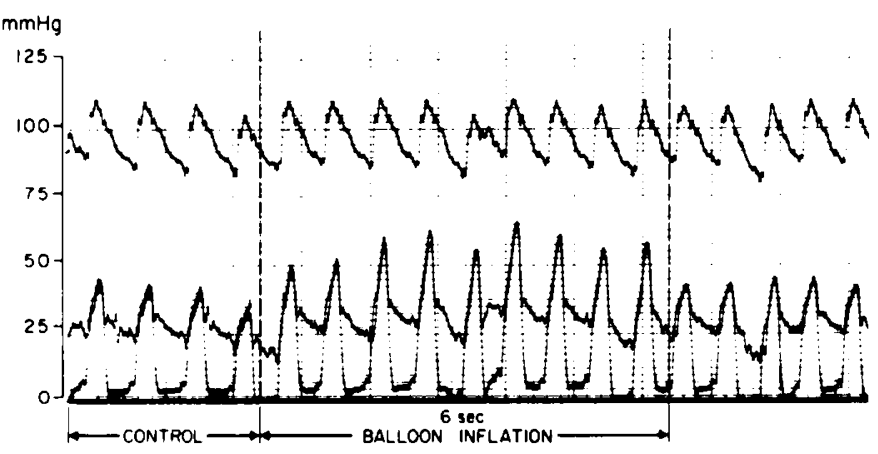

Fig. 3. Response to main pulmonary artery distention in an awake 3. month-old lamb. Shown are simultaneously recorded aortic pressure (upper tracing) and pulmonary arterial and right ventricular pressures (lower tracings). The portion of the record between the two vertical lines is the response to the main pulmonary artery distention. In this experiment, the pulmonary artery pressure increases from $37 / 20$ to $57 / 26 \mathrm{~mm} \mathrm{Hg}$ without appreciably affecting aortic or right ventricular diastolic pressures.

5), whereas neither aortic pressure nor heart rate were significantly affected by MPA distention (Table 1). However, cardiac output was significantly decreased from $1.81 \pm 0.28$ to $1.21 \pm 0.18$ liters/ min $(P<0.05)$ (Table 1$)$, thus pulmonary resistance markedly increased from $24.81 \pm 6.16$ to $49.53 \pm 11.07 \mathrm{RU}(P<0.05)$. This increase $(117 \%)$ in pulmonary resistance in the newborn lambs was significantly greater than the resistance responses obtained from animals in the two older groups by analysis of variance ( $P$ $<0.05$ ) (Figs. 6 and 7).

An example showing how pronounced this hypertensive response can be in the full-term newborn lamb ( $2 \mathrm{hr}$ old $)$ is presented in Figure 2. Similar "hyperreactive" responses were observed in approximately $30 \%$ of the newborn animals tested. In some new- born lambs, the pulmonary artery pressure did not return to control levels after balloon deflation but remained markedly elevated above control levels for periods as long as $\mathbf{2 ~ h r}$.

\section{DISCUSSION}

Previous investigators, utilized both balloons $(1,18,27,29,34)$ and nonocclusive inflatable cuffed cylinders with fixed lumens $(18,29)$ to distend unilaterally the branches of the pulmonary artery. They invariably reported an increase in pulmonary artery pressure $(1,18,27,29,34)$ and resistance $(1,18,29,34)$ in adult dogs. More recently, we have demonstrated that stepwise balloon inflation in the main pulmonary artery of the awake adult dog results in step increases in the pulmonary artery pressure downstream from the balloon $(19,20,22)$. Because a marked increase in pressure occurred in the absence of any appreciable change in right ventricular end-diastolic pressure, left atrial pressure, aortic pressure, and cardiac output, the pulmonary vascular resistance rose significantly. Further, we demonstrated that this pulmonary hypertensive response is an apparent positive feedback reflex event most probably mediated via stretch receptors located near the bifurcation of the main pulmonary artery and the sympathetic nerves $(19,20)$.

In the present investigation as in previous investigations in the adult $\operatorname{dog}(19,20,22)$, distention of the main pulmonary artery in newborn, young, and adult sheep induced pulmonary hypertension as a consequence of increased pulmonary vascular resistance. The quick hypertensive response, within two heart beats, which was not altered by breathing $100 \%$ oxygen suggests that this reflex is independent of hypoxic mechanisms.

The response to pulmonary artery distention obtained in the adult sheep was essentially similar to that previously reported in the adult dog $(19,20,22)$. The downstream elevation in pulmonary artery pressure (Fig. 4) occurred in the absence of significant change in the cardiac output (Table 1). The small but significant 


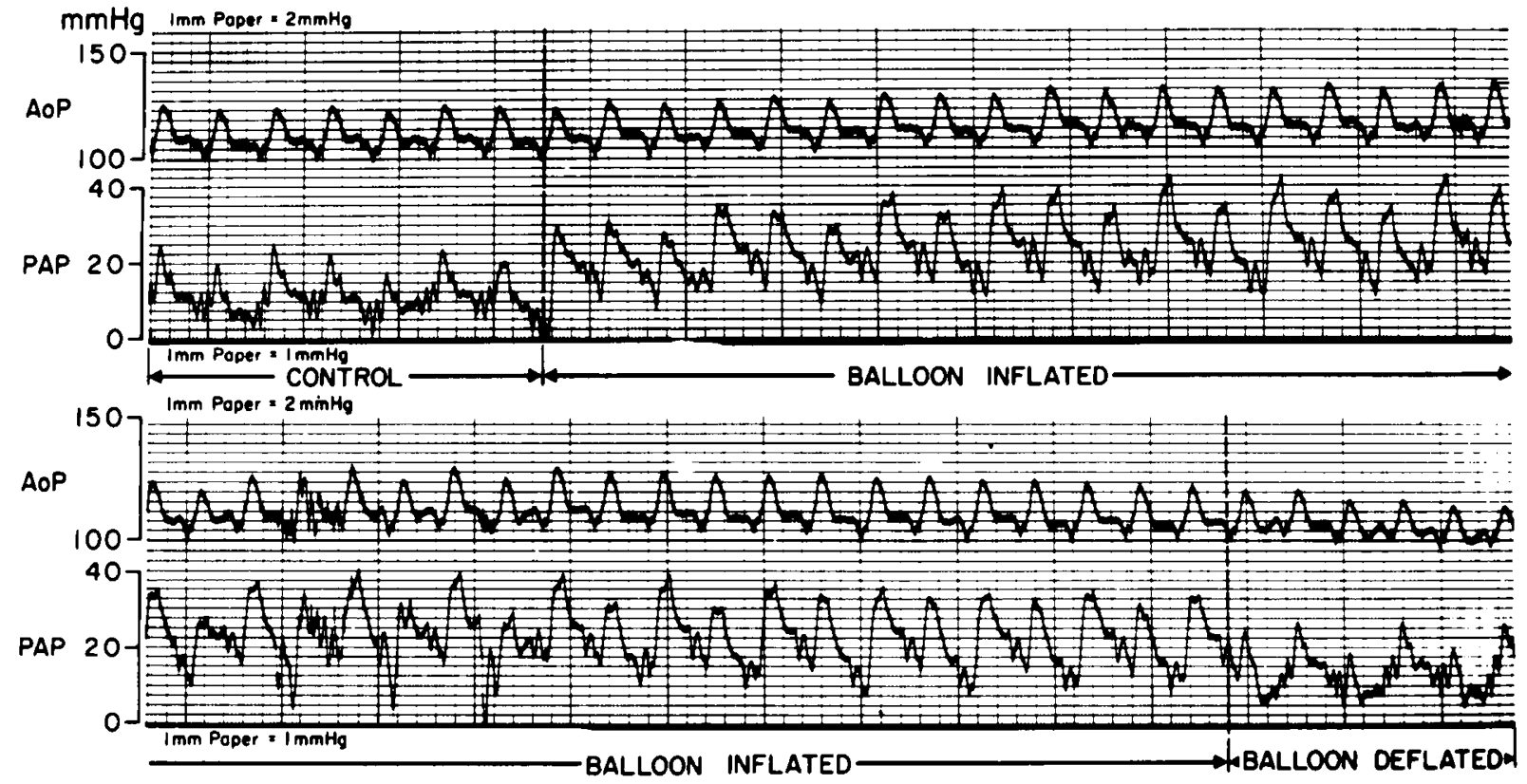

Fig. 4. Response to main pulmonary artery distention in an awake adult sheep. Upper panel of this record shows the onset of the response, whereas the lower panel shows the off response. Distention of the main pulmonary artery in an adult sheep caused an increase in both the systolic and diastolic pulmonary artery pressure. In this experiment, the pulmonary artery pressure increased from $22 / 8$ to $40 / 17 \mathrm{~mm} \mathrm{Hg}$, whereas aortic pressure was not significantly altered.
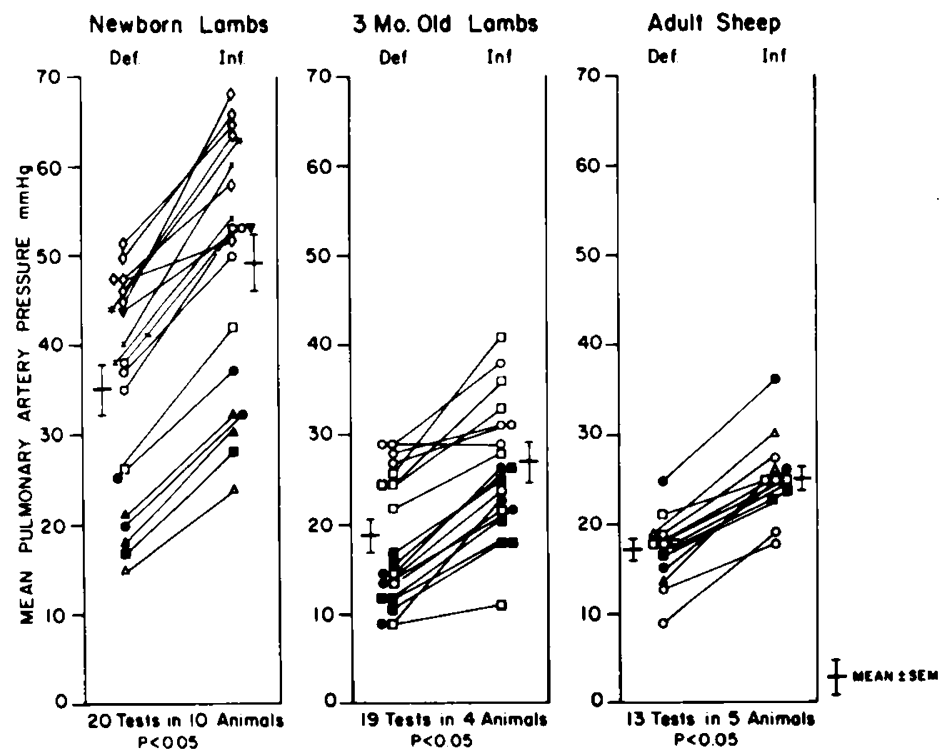

Fig. 5. Effect of MPA distention on mean pulmonary artery pressure. All experiments are shown for every animal tested. Within each group, newborn, 3 months old, and adult, each animal has its own symbol. All measurements of pressure were made distal to the balloon (see text).

increase in aortic pressure is probably the result of the small but significant increase in heart rate.

The responses to main pulmonary artery distention obtained in the 3-month-old lambs (Fig. 3) were, with minor differences, similar to those obtained in the adult animals. In these animals, aortic pressure was not significantly altered but both heart rate and cardiac output were slightly increased $(P<0.05)$ (Table 1$)$. In addition, measurements of right ventricular pressure in this group suggests that main pulmonary artery distention did not appreciably alter right ventricular end-diastolic pressure (Fig. 3). Finally, the percentage of increase in pulmonary vascular resistance obtained in these animals was not significantly different from that obtained in the adult animals $(P>0.05$ by analysis of variance) (Fig. 7).

However, in the newborn group, distention of the main pul- monary artery caused marked increases in pulmonary artery pressure in the presence of a significantly decreased cardiac output (Figs. 2 and 5; Table 1). Cardiac output was determined only in those newborn lambs without demonstrable intracardiac shunts (16). Thus, the newborn group demonstrated markedly greater increases in downstream pulmonary resistance than in either of the two older animal groups (Figs. 6 and 7). Neither aortic pressure nor heart rate was altered by main pulmonary artery distention in this group (Table 1). Because the ductus arterious was functionally closed in the newborn lambs at the time of the study, it was not unusual for main pulmonary artery distention to raise the mean pulmonary artery pressure considerably higher than aortic systolic levels (Fig. 2). In addition, we recorded several instances in the newborn lambs and one in a 3-month-old lamb in which the pulmonary artery pressure remained markedly elevated above 
Table 1. Effects of main pulmonary artery distention ${ }^{1}$ on mean aortic pressure, heart rate, and cardiac output, in sheep of three age

\begin{tabular}{|c|c|c|c|c|c|c|}
\hline \multirow[b]{3}{*}{ Group } & & & grou & & & \\
\hline & \multicolumn{2}{|c|}{$\mathrm{AP}^{2}(\mathrm{~mm} \mathrm{Hg})$} & \multicolumn{2}{|c|}{ HR (beats/min) } & \multicolumn{2}{|c|}{ Q̀ (liters/min) } \\
\hline & Deflated & Inflated & Deflated & Inflated & Deflated & Inflated \\
\hline \multirow{2}{*}{$\begin{array}{c}\text { Newborn } \\
\text { lambs }\end{array}$} & $56 \pm 3^{3}$ & $57 \pm 3$ & $219 \pm 15$ & $226 \pm 67$ & $1.81 \pm 0.28$ & $1.21^{4} \pm 0.18$ \\
\hline & \multicolumn{2}{|c|}{$(10)^{5}$} & \multicolumn{2}{|c|}{ (10) } & \multicolumn{2}{|c|}{ (6) } \\
\hline \multirow{2}{*}{$\begin{array}{l}\text { 3-mo.-old } \\
\text { lambs }\end{array}$} & $93 \pm 4$ & $94 \pm 3$ & $121 \pm 4$ & $128^{4} \pm 5$ & $3.98 \pm 0.34$ & $4.35^{4} \pm 0.28$ \\
\hline & \multicolumn{2}{|c|}{ (4) } & \multicolumn{2}{|c|}{ (4) } & \multicolumn{2}{|c|}{ (4) } \\
\hline Adult sheep & (5) & $132^{4} \pm 5$ & $109 \pm 13$ & $116^{4} \pm 12$ & $8.17 \pm 1.15$ & $8.26 \pm 1.01$ \\
\hline
\end{tabular}

${ }^{1}$ MPA distention is produced by a partially inflated balloon in the main pulmonary artery.

${ }^{2} \mathrm{AP}$, aortic pressure; $H R$, heart rate; $\dot{Q}$, Cardiac output.

${ }^{3}$ Mean \pm S.E.

${ }^{4} P<0.05$.

${ }^{5}$ Numbers in parentheses, number of animals in group.
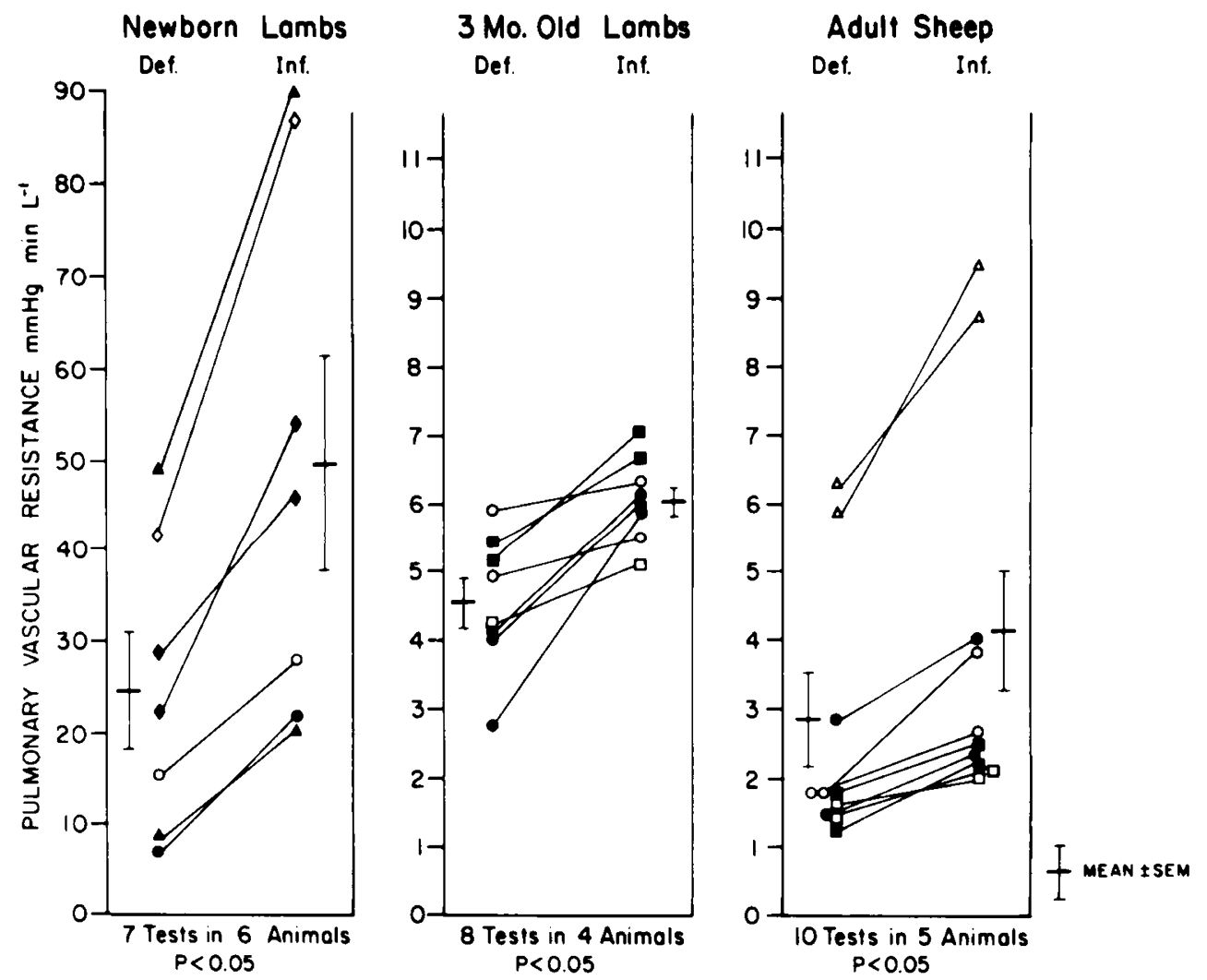

Fig. 6. Effect of MPA distention on pulmonary vascular resistance. All experiments are shown for every animal within each group; each animal has its own symbol. In the newborn lamb group resistance was calculated only for those animals in which reliable cardiac output measurements could be made (i.e., animals without intracardiac shunts) (see text). The newborn lamb group is on a different scale from the other two groups.

control levels after deflation of the intrapulmonary artery balloon. In some animals, this prolonged hypertensive response was sustained for periods of $2 \mathrm{hr}$. In most cases, a prolonged hypertensive response usually precluded the performance of more than a single test in that animal. The eventual decline of pulmonary artery pressure to near control levels was always gradual.

Previous investigators $(4-6,13-15,28)$ have demonstrated in mammals, including lambs, that during fetal life the pulmonary vascular resistance is greater than the systemic vascular resistance and is associated with the presence of highly muscular pulmonary arteries $(10,15,17,23,25,28,32,36)$. Because of this very high pulmonary vascular resistance, blood flow bypasses the developing fetal lungs and is shunted to the descending aorta via the ductus arteriosus, thus promoting fetal gas exchange by directing blood with slightly lower $\mathrm{PO}_{2}$ toward the placenta where fetal gas exchange occurs.

After birth with the establishment of respiration, the neonatal pulmonary vascular resistance decreases quickly at first and then more slowly $(2,12,15,17,32,33,36)$. The amount of the initial drop and the rate of the further decline in pulmonary vascular resistance varies from species to species $(12,15,25,32,33,36)$. In addition, after birth, the hypertrophied muscle of the pulmonary vessels gradually atrophies to normal adult levels over a period lasting up to several weeks depending on the species $(17,36)$. The 


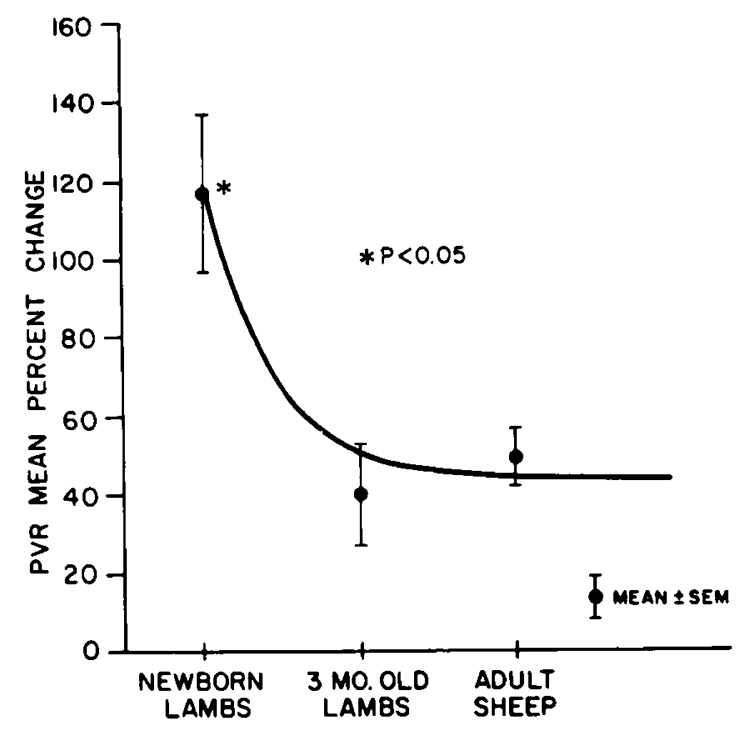

Fig. 7. Mean percentage of change in pulmonary vascular resistance $(P V R)$ induced by MPA distention. In the newborn group, the percentage of increase in pulmonary vascular resistance is more than two times greater than that of adult and 3-month-old sheep. However, this response to MPA distention decreases to adult levels within 3 months after birth. ${ }^{*}$, mean percentage of change for the newborn lambs was significantly greater than the changes obtained in the other two groups. The mean percentage of change in pulmonary vascular resistance for the 3-month-old lambs was not significantly different from that of the adult sheep. (Statistical significance of these data was determined by analysis of variance.) Curved line shown in the figure was drawn by inspection to emphasize the observed difference in percentage of changes in pulmonary vascular resistance between the three age groups studied.

gradual decline in the pulmonary arterial pressure and resistance has been correlated with the loss of the hypertrophied pulmonary vascular smooth muscle $(10,15,17,26,30)$. Therefore, in the present study, it was not surprising to find that before distention of the main pulmonary artery, pressures were greater in the newborn group than in either the 3-month-old or the adult group. The very high levels of pulmonary artery pressure obtained in newborn lambs is probably caused by the constriction of the normally thickened smooth muscle in small pulmonary vessels. The animals in the 3-month-old group seem to be physiologically intermediate between the newborn lambs and the adult sheep. Whereas the resting pulmonary vascular resistance of this group was higher than that of the adult group (Fig. 6), their response to main pulmonary artery distention was not significantly different (Fig. 7). The slightly higher resting pulmonary vascular resistance observed in the 3-month-old lambs can be attributed to either the presence of relatively more pulmonary vascular smooth muscle (35) and/or more sympathetic adrenergic innervation of the pulmonary vessels. That distention of the main pulmonary artery produced similar changes in the pulmonary vascular resistance in the 3-month-old and adult groups suggests that the responsiveness to distention declines faster with increasing age than the pulmonary vascular muscle decreases. Therefore, the possibility exists that with increasing age either the threshold of this distention reflex increases or the relative pulmonary vascular innervation decreases.

Similarities between the pulmonary vascular response to distention of the main pulmonary artery and the response to hypoxia are evident. Large increases in pulmonary vascular resistance have been shown to be produced by exposing animals to acute or chronic $(3,4,13,30-32)$ alveolar hypoxia. In addition, as with the main pulmonary artery distention, the pulmonary arterial pressure and vascular resistance responses to hypoxia are greater in newborn and young animals than in adult animals $(24,30)$. It is of great interest in these experiments that even in lambs breathing
$100 \%$ oxygen distention of the main pulmonary artery generated marked increases in pulmonary artery pressure and resistance. Therefore, although these two types of pulmonary vasoconstriction can most likely be produced independently of one another (21), the possibility exists that during fetal and neonatal life some type of interaction occurs. Consider the following: acute asphyxia in the mature fetal lamb causes pulmonary vasoconstriction which persists after denervation of the lungs (8). However, certain evidence suggests that hypoxia may not act alone to control fetal pulmonary vascular resistance. Colebatch et al. (11) demonstrated that sympathectomy caused pulmonary vasodilation in the normal mature fetal lamb. Moreover, stimulation of the sympathetic nerves to the lung (T3-T5) caused pulmonary vasoconstriction. Even at 80 to 90 days gestation, sympathetic stimulation can reduce pulmonary blood flow by $75 \%$. In addition, fetal lung vessels can be constricted by small amounts of epinephrine and norepinephrine. Campbell $e t$ al. (9) in a series of cross-circulation experiments in fetal lambs demonstrated intense pulmonary vasoconstriction in the recipient lamb by inducing severe asphyxia in the donor lamb. However, asphyxia in the recipient lamb alone while its lungs were perfused with normal blood also resulted in pulmonary vasoconstriction. This vasoconstriction could be abolished either by hexamethonium or by cutting the sympathetic supply to the lungs. Additionally, they observed that a small amount of reflex vasodilation occurred during asphyxia after the sympathetic nerves to the lung had been cut. Therefore, we postulate that hypoxia may interact either additively or synergistically with the distention reflex to sustain high pulmonary vascular resistance in the fetus.

In conclusion, the data demonstrate that distention of the proximal main pulmonary artery, near the bifurcation, in the sheep evokes a positive feedback reflex mechanism (similar to that in the dog) which operates to increase downstream pulmonary vascular resistance. Further, the data show that the hemodynamic response to this reflex is greater in newborn than in older sheep. Consequently, the data strongly suggest that this reflex may contribute, in conjunction with hypoxia, to the maintenance of high pulmonary vascular resistance during fetal life. Such a positive feedback reflex is ideally suited to the fetus because it would help to promote flow across the ductus arteriosus toward the aorta and placenta. The relationship between the patent ductus arteriosus and this pulmonary artery distention reflex is such that even if the pulmonary vasculature becomes totally constricted flow would still continue via the ductus arteriosus. Thus, the patent ductus arteriosus is very likely the major factor operating to modulate the effects of evoking this positive feedback mechanism. We postulate that this reflex may play a role in the maintenance of persistant pulmonary hypertension seen in the neonatal persistent fetal circulation syndrome (7). Further, we postulate that in the absence of a patent ductus arteriosus, as in adults, the induction of a pulmonary positive feedback reflex could result in the uncontrolled production of pulmonary hypertension. Therefore, distention of the pulmonary artery may also play an underlying role in the pathogenesis of adult primary pulmonary hypertensive states.

\section{REFERENCES AND NOTES}

1. Aramendia, P., Taquini, C. M., Forcade, A., and Taquini, A. C.: Reflex vasomotor activity during unilateral occlusion of the pulmonary artery. Am. Heart J., 66: 53 (1963).

2. Assali, N. S., Bekey, G. A., and Morrison, L. W.: Fetal and neonatal circulation. In: N. S. Assali: Biology of Gestation, Vol. II, pp. 51-116 (Academic Press Inc., New York, 1968)

3. Assali, N. S., and Brinkman, C. R.: Control of systemic and pulmonary vasomotor tone before and after Birth. In: C. M. Bloor: Comparative Pathophysiology of Circulatory Disturbances. pp. 13-37 (Plenum Publishing Corp., New York, 1972).

4. Assali, N. S., and Morris, J. A.: Maternal and fetal circulations and their interrelationships. Obstet. Gynecol. Surv., 19: 923 (1964).

5. Barclay, A. E., Franklin, K. J., and Prichard, M. M. L.: The fetal circulation, (Charles C Thomas, Publisher, Springfield, IL, 1945).

6. Barcroft, J.: Researches on Prenatal Life. Vol. I (Blackwell Scientific Publications, Oxford, England, 1946).

7. Baylen, B. G., Emmanouilides, G. C., Juratsch, C. E., Yoshida. Y., French, W. 
J., and Criley, J. M.: Main pulmonary artery distention: a potential mechanism for acute pulmonary hypertension in the human newborn. J. Pediatrics, 96: 540 (1980).

8. Born, G. V. R., Dawes, G. S., and Mott, J. C.: The viability of premature lambs J. Physiol. (Lond.), 130: 191 (1955).

9. Campbell, A. G. M., Cockburn, F., Dawes, G. S., and Milligan, J. E.: Pulmonary blood flow and cross-circulation between twin feotal lambs. J. Physiol. (Lond.) 186: 96 (1966).

10. Civin, W. H., and Edwards, J. E.: The postnatal structural changes in the intrapulmonary arteries and arterioles. A. M. A. Arch. Pathol., 51: 192 (195I).

11. Colebatch, H. J. H., Dawes, G. S., Goodwin, J. W., and Nadeau, R. A.: The nervous control of the circulation in the feotal and newly expanded lungs of the lamb. J. Physiol. (Lond.), 178: 544 (1965).

12. Dawes, G. S.: Changes in circulation at birth. Br. M. Bull., I7: 148 (1961).

13. Dawes, G. S.: The pulmonary circulation in the foetus and newborn. In: Foetal and Neonatal Physiology-A Comparative Study of the Changes at Birth. pp. 79-89 (Year Book Medical Publishers Inc., Chicago, 1968)

14. Dawes, G. S., Mott, J. C., and Widdicombe, J. G.: The fetal circulation in the lamb. J. Physiol. (Lond.), 126: 563 (1954).

15. Emmanouilides, G. C., Moss, A. J., Duffie, E. R., Jr., and Adams, F. H.: Pulmonary arterial pressure changes in human newborn infants from birth to 3 days of age. J. Pediatrics, 65: 327 (1964).

16. Emmanouilides, G. C.. Moss, A. J., Monset-Couchard, M., Marcano, B. A., and Rzeznic, B.: Cardiac output in newborn infants. Biol. Neonate, 15: 186 (1970).

17. Harris, P., and Heath, D.: The human pulmonary circulation, 2 nd ed., pp. 211 225 (Churchill Livingston. Edinburgh, 1977).

18. Hyman, A. L.: Pulmonary vasoconstriction due to non-occlusive distention of the large pulmonary arteries in the dog. Circ. Res., 23: 401 (1968).

19. Juratsch, C. E., Jengo, J. A., Castagna, J., and Laks, M. M.: Experimenta pulmonary hypertension produced by surgical and chemical denervation of the pulmonary vasculature. Chest. 77: 525 (1980).

20. Juratsch, C. E., Jengo, J. A., and Laks, M. M.: Role of the autonomic nervous system and pulmonary artery receptors in production of experimental pulmonary hypertension. Chest, 71 S: 265 (1977).

21. Juratsch, C. E., Manohar, M., Hockett, D., Laks, M., and Will, J. A.: Effects of hyperoxia and hypoxia on reflex pulmonary hypertension $(\mathrm{PH})$ in awake calves and ponies. Physiologist, 21: 62 (1978).

22. Laks, M. M., Juratsch, C. E., Garner, D., Beazell, J., and Criley, J. M.: Acute pulmonary arterial hypertension produced by distention of the main pulmonary artery in the conscious dog. Chest, 68: 806 (1975).

23. Larroche, J. C., Nodot, A., and Minkowski, A.: Development des arteres et arterioles pulmonaires de la periode faetale a la period neonatale. Biol. Neonat., 1: 37 (1959).

24. Lewis, A. B., Heymann, M. A., and Rudlolph. A. M.: Gestational changes in

Copyright $(\odot 1980$ International Pediatric Research Foundation, Inc

$0031-3998 / 80 / 1412-1332 \$ 02.00 / 0$ pulmonary vascular responses in fetal lambs in utero. Circ. Res., 39: 536 (1976) 25. Lind, J.: Human fetal and neonatal circulation. Eur. J. Cardiol., 5: 265 (1977).

26. Lucas, R. V., Jr., St. Geme, J. W., Jr., Anderson, R. C., Adams, P., Jr., and Ferguson, D. J.: Maturation of the pulmonary vascular bed. A physiologic and anatomic correlation in infants and children. Am. J. Dis. Child., 101: 467 (1961).

27. Murao, M., Ondera, S., Homa, T., Katoaka, N., Takabori, T., Moutoni, Y. Koboyashi, T., and Makino, $M$.: Effects of occlusion and further distention of unilateral pulmonary artery with an inflatable balloon upon systemic and pulmonary hemodynamics. Jpn. Heart J., 10: 59 (1969).

28. Murray, J. F.: The normal lung. The basis for diagnosis and treatment of pulmonary disease. pp. 8-10 (W. B. Saunders Company, Philadelphia, 1976)

29. Osorio, J., and Russek. M.: Reflex changes on the pulmonary and systemic pressures elicited by stimulation of baroreceptors in the pulmonary artery. Circ. Res., 10: 664 (1962).

30. Reeves, J. T., and Leathers, J. E.: Circulatory changes following birth of the calf and the effect of hypoxia. Circ. Res., 15: 343 (1964).

31. Reeves, J. T., and Leathers, J. E.: Hypoxic pulmonary hypertension of the calf with denervation of the lungs. J. Appl. Physiol., 19: 976 (1964).

32. Rudolph, A. M.: The changes in the circulation after birth-their importance in congenital heart disease. Circulation, 41: 343 (1970).

33. Rudolph, A. M., Auld, P. A., Golinko, R. J., and Paul, M. H.: Pulmonary vascular adjustments in the neonatal period. Pediatrics, 28: 28 (1961).

34. Ueda, H., Murado, M., Momose, T., Hatano, S., Koike, S., Shiraishi, T., Kuroiwa, A., Sugimoto, T. F., Uzawa, T., Shimomura, K., Saito, Y., and Yamada, T. Effects of unilateral pulmonary artery or vein distention with a balloon on the pulmonary and femoral arterial pressures in anesthetized dogs. Jpn. Heart J. 6: 428 (1965).

35. Wagenvoor, C. A., Neufeld, H. N., and Edwards, J. E.: The structure of the pulmonary arterial tree in fetal and early postnatal life. Lab. Invest., 10: 751 (1961)

36. Wagenvoort, C. A., and Wagenvoort, N.: Pathology of pulmonary hypertension. pp. 5-7 (John Wiley \& Sons, Inc., New York, 1977).

37. The authors thank William Walby for his technical assistance and for providing the excellent illustrations. We also wish to thank Grace Fredrickson for her superb typing and help in editing the manuscript.

38. Requests for reprints should be addressed to: Craig E. Juratsch, Ph.D., Division of Cardiology, Harbor-UCLA Medical Center, 1000 West Carson Street. Torrance, CA 90509 (USA).

39. This research was supported by NIH Grant HL 18371 and in part by the American Heart Association, Greater Los Angeles Affiliate Grants 529 and 558.

40. Received for publication August 6, 1979

41. Accepted for publication March 19, 1980.

Printed in U.S.A. 